\title{
Novel assessment method of heavy metal pollution in surface water: A case study of Yangping River in Lingbao City, China
}

\author{
Yingran $\mathrm{Liu}^{1,2+}$, Hongming $\mathrm{Yu}^{1}$, Yu Sun${ }^{2}$, Juan $\mathrm{Chen}^{2}$ \\ ${ }^{1}$ Faculty of Engineering, China University of Geosciences, Wuhan 430074, China \\ ${ }^{2}$ The Fourth Geological Exploration Institute of Henan Geology and Mineral Bureau, Zhengzhou 450001, China
}

\begin{abstract}
The primary purpose of this research is to understand those elements that define heavy metals contamination and to propose a novel assessment method based on principal component analysis (PCA) in the Yangping River region of Lingbao City, China. This paper makes detailed calculations regarding such factors the single-factor assessment $\left(\mathrm{P}_{i}\right)$ and Nemerow's multi-factor index $\left(\mathrm{P}_{N}\right)$ of heavy metals found in the surface water of the Yangping River. The maximum values of $\mathrm{P}_{i}(\mathrm{Cd})$ and $\mathrm{P}_{i}(\mathrm{~Pb})$ were determined to be 892.000 and 113.800 respectively. The maximum value of $\mathrm{P}_{N}$ was calculated to be 639.836. The results of Pearson's correlation analysis, hierarchical cluster analysis, and PCA indicated heavy metal groupings as follows: $\mathrm{Cu}, \mathrm{Pb}, \mathrm{Zn}$ and $\mathrm{As}, \mathrm{Hg}, \mathrm{Cd}$. The PCA-based pollution index $\left(\mathrm{P}_{a n}\right)$ of samplings was subsequently calculated. The relative coefficient square was valued at 0.996 between $\mathrm{P}_{a n}$ and $\mathrm{P}_{N}$, which indicated that $\mathrm{P}_{a n}$ is able to serve as a new heavy metal pollution index; not only this index able to eliminate the influence of the maximum value of $\mathrm{P}_{i}$, but further, this index contains the principal component elements needed to evaluate heavy metal pollution levels.
\end{abstract}

Keywords: Heavy metals contamination, Hierarchical cluster analysis (HCA), Pollution evaluation, Principal component analysis (PCA), Yangping River

\section{Introduction}

The term 'heavy metals' generally refers to such metals as lead $(\mathrm{Pb})$, zinc $(\mathrm{Zn})$, cadmium $(\mathrm{Cd})$, mercury $(\mathrm{Hg})$ and chromium $(\mathrm{Cr})$, or those metallic elements that yield a density greater than $5 \mathrm{~g} / \mathrm{cm}^{3}$ [1]. Heavy metal pollution is often associated with variables of concealment, persistency and irreversibility [2]. This pollution not only degrades the quality of the atmosphere, water bodies, and agricultural outputs, but also threatens the health and well-being of both animals and human beings, particularly by way of the food chain [2-4]. At present, the heavy metal pollution of river water has become an urgent problem on the international level [5, 6]. An increasing concentration of metals continues to be found in riverbeds, specifically in those areas inhabited by living species. Due to such processes as biomagnification, higher concentrations of heavy metals are found in the bodies of animals that are closer to the top of the food chain [7].

Assessment indexes of heavy metal pollution included the following variables: single index factor $\left(P_{i}\right)$, Nemerow's pollution index
$\left(P_{N}\right)$, [8-9] potential ecological risk index $(R)$ [5], enrichment factor $(E F)$ [5, 10-13], contamination factor $(C F)[6,14]$, geoaccumulation index $\left(I_{\text {geo }}\right)[5,6,10,15]$, heavy metal evaluation index $(H E I)$, heavy metal pollution index $(H P)$, contamination index $\left(C_{d}\right)$ [16], pollution load index $(P L I)$ [12]. The arithmetic methods used to calculated both $\mathrm{P}_{i}$ and $C F$ are simply yielded by the computation basis of $P_{N}$ and $P L I$ respectively. EF represents the value that evaluates anthropogenic influences on heavy metals in sediments; the measurement uses aluminum (Al) as a conservative element. $R I$ considers the toxicity of the pollutant as a means of evaluating the ecological risk; the value does so by comparing the concentration of the pollutant with the background value [8]. $I_{\text {geo }}$ can be used to distinguish the effects human activities have on the environment [17]. The afore mentioned indexes $R I, E F$, and $I_{\text {geo }}$ are used to evaluate sediment or soil. Both the HEI and HPI indexes, in contrast are used to evaluate drinking water. These statistics, however, must modify the threshold value used to assess pollution levels, these indexes are calculated based on measured concentration of samples, values which can not reflect the principal contaminant elements.
This is an Open Access article distributed under the terms of the Creative Commons Attribution Non-Commercial License (http://creativecommons.org/licenses/by-nc/3.0/) which permits unrestricted non-commercial use, distribution, and reproduction in any medium, provided the original work is properly cited.
Received January 27, 2016 Accepted September 6, 2016

${ }^{\dagger}$ Corresponding author

Email: liuyingran@126.com

Tel: +86-18339219612

Copyright (C) 2017 Korean Society of Environmental Engineers 
The central idea of principal component analysis (PCA) is to reduce the dimensionality of data [18]. PCA can transform raw data into uncorrelated variables representing linear combinations of the raw data [19]. It can identify the heavy metal pollution sources in sediment samples and river water depending on the methods used [5, 10, 20]. Hierarchical cluster analysis (HCA) is a statistical method of analysis allows for data to be grouped into clusters based on observed similarities [21]. HCA was used to detect these similarities and to form groups between the sampling sites [22]. In order to simplify the procedure and reduce the analytical costs of the water quality evaluation, a modified water quality index $\left(W Q I_{\min }\right)$ was introduced based on both PCA and correlation analyses of the water parameters [23].

Because of the fluidity of river water, real-time monitoring for river water quality is one important component of heavy metal pollution investigation. Moving forward, it becomes necessary to propose a rapid detection method. Such a method becomes effective in recognizing principal contaminant elements and real-time water quality during the monitoring of raw data. The objectives of this article are: (1) to identify the sources of six heavy metals contaminations in the Yangping River; (2) to propose the creation and use of real-time monitoring of primary heavy metal elements in the future; (3) to propose a novel assessment method of heavy metals contamination.

\section{Materials and Methods}

\subsection{Study Area and Collection of Water Samples}

The Yangping River, which flows through the town of Yangping, is a tributaries of the Yellow River located in Lingbao City, China. The Yangping River basin is located roughly between latitude coordinates $34^{\circ} 28^{\prime} \mathrm{N}$ and $34^{\circ} 36^{\prime} \mathrm{N}$ and logitude coordinates $110^{\circ} 43^{\prime} \mathrm{E}$ and $110^{\circ} 38^{\prime} \mathrm{E}$ (Fig. 1). The direction of the river is determined by the terrain of Lingbao City, which is higher in the south than in the north. Lingbao City is one of the primary gold producing areas in China, as gold mining enterprises occupy approximately $76 \%$ of the entire city. With the rapid development of gold mining practices, surface water heavy metal pollution has become an increasingly relevant environmental problem in the region. While many rivers have been polluted by gold mining in Lingbao City, the Yangping River is polluted more seriously than other rivers in the region.

Samples of water were collected from levels $10 \mathrm{~cm}$ below the water's surface and stored in $100 \mathrm{~mL}$ polyethylene bottles at each site.

Each bottle was washed more than three times in order to guarantee the accuracy of monitoring at each site. Collected samples were acidified with concentrated (conc.) $\mathrm{HNO}_{3}$ to $\mathrm{pH}<2$. Samples were kept on ice and brought to the laboratory, where they were stored for further analysis in a refrigerator with a temperature of four degrees Celsius. The coordinate of each site were measured by a global positioning system (GPS). Fig. 1 illustrates each site's relative location - upstream or downstream - from the Yangping River. Two sample bottles were collected at each site for the purpose of parallel examination.

\subsection{Analysis and Process of Sampling}

In order to analyze the presence of heavy metal, $100 \mathrm{~mL}$ of acid treated samples were concentrated. If the solution remained feculent, it required the addition of $\mathrm{HNO}_{3}$ until the color appeared constant. Following this step, $\mathrm{HCl}(2 \%)$ was added to dissolve any salt in the sample until it reached heating condition. After the heating treatment, the mixture was concentrated to 2 or 3 $\mathrm{mL}$ and diluted with water to reach $100 \mathrm{~mL}$ for the analysis of $\mathrm{Cu}, \mathrm{Cd}, \mathrm{Zn}$ and $\mathrm{Pb}$. The content of aforementioned metals was tested for by a graphite furnace atomic absorption spectrometer (SOLAR969Z, Thermo Electron Corporation, USA). The other 10

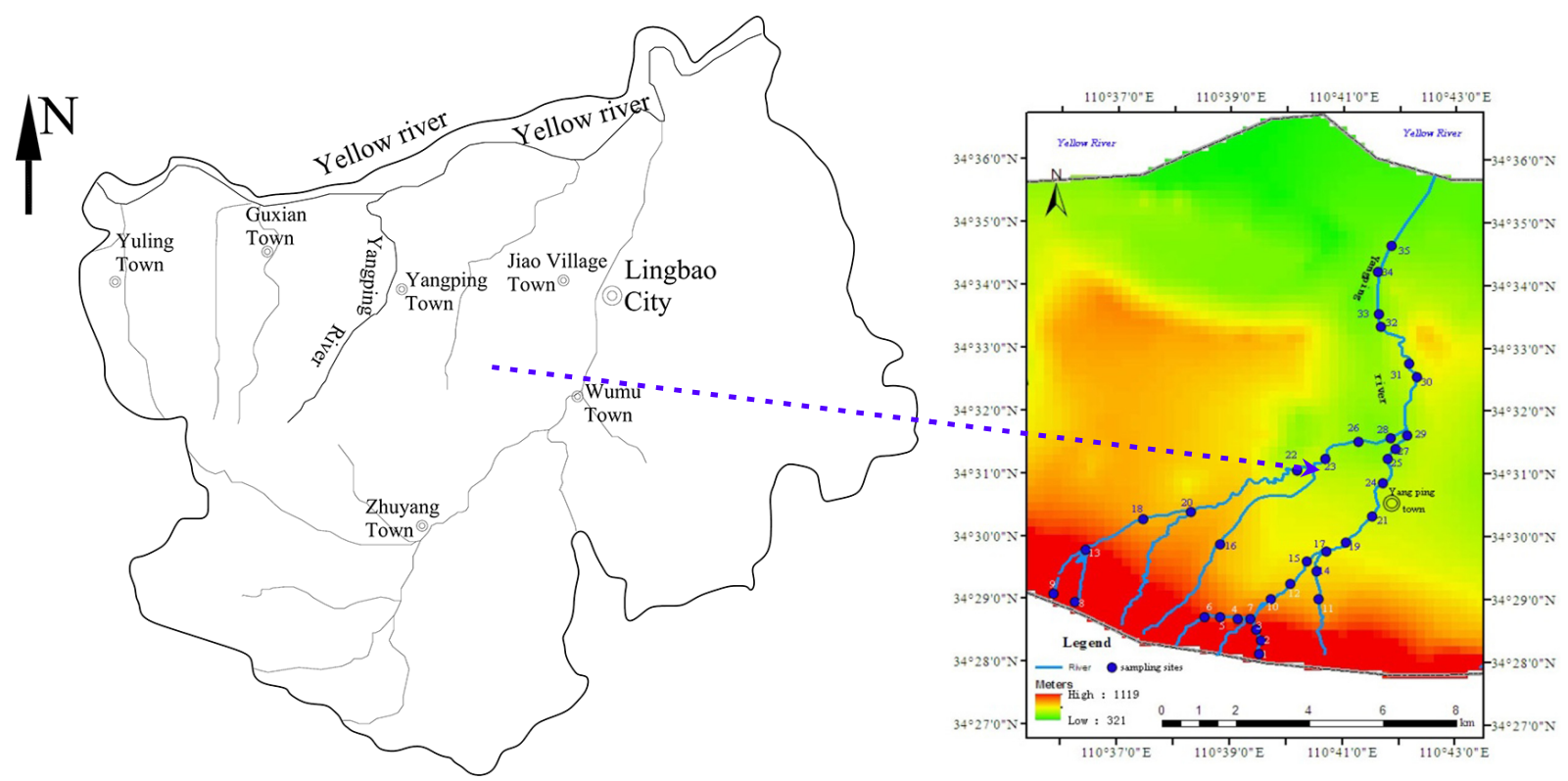

Fig. 1. Sampling and site of Yangping River. 
$\mathrm{mL}$ water samples of $\mathrm{Hg}$ and As were mixed with $5 \mathrm{~mL}$ of hydrochloric acid and $10 \%$ of $10 \mathrm{~mL}$ thiourea in order to be diluted to $100 \mathrm{~mL}$ required for analysis An Atomic Fluorescence Spectrophotometer (AFS-8330, Beijing Titan Instrument Co. Ltd, China) detected both elements. All of the reagents were characterized as guaranteed reagents (GR) in the process of testing and the selected water was ultrapure [14].

\subsection{Pollution Assessment Methods of Heavy Metals}

The most basic assessment method used is the single factor index, as this method is the most straightforward [8]. The pollution index for a single pollutant was established according to Eq. (1):

$$
P_{i}=C_{i} / S_{i}
$$

Where, $P_{i}$ is the single factor pollution index; $C_{i}(\mathrm{mg} / \mathrm{kg})$ is the measured concentration of heavy metals; and $S_{i}(\mathrm{mg} / \mathrm{kg})$ is the standard value of the pollutants. The value of the single factor index $P_{i}<1$ indicates clean lines, 1-2 is regarded as low cleanliness, 2-3 is moderate, and $P_{i}>3$ indicates high levels of cleanliness [8].

The Nemerow's pollution index was used to evaluate the comprehensive pollution status of heavy metals [8]. This index is the most common and comprehensive pollution evaluation method. Not only it is reflected the single factor index $P_{i}$, but it emphasizes the influence of high concentration of heavy metal elements on environmental quality and eliminates the deficiency of average value on evaluation. The Nemerow's pollution index can be calculated using Eq. (2):

$$
P_{N}=\sqrt{\frac{\left(\max P_{i}\right)^{2}+\left(\bar{P}_{i}\right)^{2}}{2}}
$$

Where $P_{N}$ is Nemerow's pollution index; $\max P_{i}$ is the maximum single pollution index among the pollutants, and $\bar{P}_{i}$ is the average mean of single pollution indexes of among all the pollutants.

The above two methods were applied in sediment and soil pollution evaluation at an early stage. However, they were also used to evaluate the heavy metal pollution of the surface water samples, which usually follows the standards of Class III of the Environmental Quality Standards of Surface Water of the People's Republic of China (GB 3838-2002) [9]. The value of Nemerow's pollution index $P_{N}<1$ indicates the clarity of water, 1-2.5 is low clarity, 2.5-7 is moderate, and $P_{N}>7$ indicates high clarity.

\subsection{The Basic Principles of Novel Assessment Method}

HCA is a statistical method used to classify data of regarding samples marked by similar characteristics; it has been used widely in the fields of medicine and biology and chemistry [16]. Among HCA, the similarity of characteristics is normally analyzed through Pearson's correlation coefficient and Euclidean distance in HCA $[17,18]$. In general, in order to ensure accuracy during classification, HCA will be used in combination with other methods of analysis, such as PCA [15]. In this study, we classified six heavy metals through HCA and PCA, both of which resulted in the same conclusion. This it indicated that it would be feasible in order to determine the groups of pollution sources.
PCA is one of the data analysis methods of the multivariate linear model. PCA is a special case of factor of analysis, as it transforms the original set of inter-correlated variables into a set of uncorrelated variables that represent linear combinations of the original variables. This is equivalent to rotating the coordinate space axes so that the covariance of each principal component (PC) is maximized. The main purpose of this technique is to remove the random deviation of principal components, so that the dimension of the complicated problem is reduced and the impact of measurement deviation is minimized [15].

PCA was applied in order to discover the source of the heavy metal pollutions. HCA was used to identify different geochemical groups, clustering together the sample stations with similar heavy metal contents [10]. PCA can obtain the proportion of the total variances that each PC represents [24]. The assessment result obtained from Nemerow's pollution index will be same when calculated with $\max P_{i}$ if there are one or two very high single pollution indexes, which might influence the authenticity of result. Therefore, we proposed a unique assessment method to evaluate the pollution level of heavy metals in this study. This method is a pollution index based on PCA and the single pollution index and is obtained via the application of by Eq. (3):

$$
P_{\alpha n}=\sum_{i=1}^{k} \frac{\alpha_{i}}{\alpha} P_{i}
$$

Where $P_{\alpha n}$ is the original pollution index of nth site; $P_{i}$ is the single pollution index of principal component; $\alpha_{i}$ is the percentage of variance contribution of $\mathrm{PC} ; \alpha$ is the accumulation percentage of variance contribution of PC; and $k$ is the number of PC. In this equation, the threshold value of pollution degree is similar to the Nemerow's pollution index.

\section{Results and Discussion}

\subsection{Statistics Analysis of Water Samples}

As illustrated in Table 1, the maximum concentrations of As, $\mathrm{Hg}, \mathrm{Cu}, \mathrm{Cd}, \mathrm{Zn}$, and $\mathrm{Pb}$ in the Yangping River were found to be $0.017,0.0009,0.027,4.460,0.095$, and $5.690 \mathrm{mg} / \mathrm{L}$, respectively; the average values calculated were 0.004, 0.0003, 0.003, 0.896, 0.016 , and $0.404 \mathrm{mg} / \mathrm{L}$; and the coefficient of variation (CVs) were found to be $119.96 \%, 93.95 \%, 146.93 \%, 126.06 \%, 127.10 \%$, and $236.95 \%$, respectively. These six heavy metals displayed moderate variation, indicating the heavy metal concentrations of the water samples varied largely within the sampling areas. The maximum values of copper and zinc are below the national standard indicated Class II and above the standard indicated for Class I . The two heavy metals satisfy the standards put forth by the World Health Organization (WHO). The maximum values of mercury and arsenic are above the national standard of Class III and IV respectively. Both the maximum and average concentrations of cadmium and lead are above the national standards of surface water pollutants indicated by Class V standards and the upper scale of WHO. Statistical analysis, thus indicated that the heavy metals pollution in the Yangping River is, indeed, an issue. 
Table 1. Heavy Metal Concentrations $(\mathrm{mg} / \mathrm{L})$ and Analytical Statistics in Surface Water Sample from the Yangping River

\begin{tabular}{|c|c|c|c|c|c|c|}
\hline Sampling NO. & As & $\mathrm{Hg}$ & $\mathrm{Cu}$ & Cd & $\mathrm{Zn}$ & $\mathbf{P b}$ \\
\hline $\mathrm{S} 1$ & 0.001 & 0.0001 & 0.001 & 0.010 & 0.005 & 0.014 \\
\hline S2 & 0.001 & 0.0001 & 0.001 & 0.005 & 0.005 & 0.008 \\
\hline S3 & 0.002 & 0.0001 & 0.001 & 0.009 & 0.004 & 0.016 \\
\hline S4 & 0.003 & 0.0001 & 0.009 & 0.380 & 0.030 & 0.420 \\
\hline S5 & 0.003 & 0.0001 & 0.009 & 0.160 & 0.036 & 0.560 \\
\hline S6 & 0.002 & 0.0001 & 0.001 & 0.021 & 0.005 & 0.055 \\
\hline S7 & 0.003 & 0.0001 & 0.004 & 0.110 & 0.016 & 0.200 \\
\hline S8 & 0.001 & 0.0001 & 0.001 & 0.007 & 0.001 & 0.048 \\
\hline S9 & 0.001 & 0.0001 & 0.008 & 0.001 & 0.005 & 0.018 \\
\hline S10 & 0.003 & 0.0002 & 0.027 & 0.540 & 0.086 & 5.690 \\
\hline S11 & 0.001 & 0.0001 & 0.001 & 1.260 & 0.008 & 0.006 \\
\hline $\mathrm{S} 12$ & 0.001 & 0.0001 & 0.002 & 0.230 & 0.008 & 0.360 \\
\hline $\mathrm{S} 13$ & 0.001 & 0.0001 & 0.001 & 0.001 & 0.001 & 0.009 \\
\hline S14 & 0.002 & 0.0001 & 0.002 & 0.600 & 0.008 & 0.460 \\
\hline $\mathrm{S} 15$ & 0.001 & 0.0001 & 0.002 & 0.420 & 0.009 & 0.420 \\
\hline S16 & 0.001 & 0.0001 & 0.001 & 0.006 & 0.005 & 0.015 \\
\hline $\mathrm{S} 17$ & 0.001 & 0.0001 & 0.002 & 0.720 & 0.010 & 0.370 \\
\hline S18 & 0.002 & 0.0001 & 0.001 & 0.005 & 0.005 & 0.007 \\
\hline S19 & 0.001 & 0.0004 & 0.002 & 2.340 & 0.015 & 0.510 \\
\hline $\mathrm{S} 20$ & 0.017 & 0.0002 & 0.009 & 0.180 & 0.095 & 0.440 \\
\hline $\mathrm{S} 21$ & 0.002 & 0.0006 & 0.002 & 2.150 & 0.013 & 0.620 \\
\hline $\mathrm{S} 22$ & 0.004 & 0.0006 & 0.001 & 0.570 & 0.015 & 0.084 \\
\hline $\mathrm{S} 23$ & 0.003 & 0.0001 & 0.001 & 0.240 & 0.005 & 0.027 \\
\hline $\mathrm{S} 24$ & 0.002 & 0.0006 & 0.002 & 4.460 & 0.016 & 0.710 \\
\hline S25 & 0.003 & 0.0004 & 0.002 & 3.080 & 0.013 & 0.390 \\
\hline S26 & 0.002 & 0.0001 & 0.002 & 0.210 & 0.008 & 0.240 \\
\hline $\mathrm{S} 27$ & 0.004 & 0.0004 & 0.002 & 3.700 & 0.017 & 0.360 \\
\hline $\mathrm{S} 28$ & 0.003 & 0.0002 & 0.005 & 0.260 & 0.023 & 1.200 \\
\hline S29 & 0.006 & 0.0003 & 0.002 & 2.120 & 0.016 & 0.380 \\
\hline S30 & 0.005 & 0.0002 & 0.001 & 0.690 & 0.009 & 0.160 \\
\hline S31 & 0.003 & 0.0001 & 0.001 & 1.030 & 0.011 & 0.057 \\
\hline S32 & 0.015 & 0.0008 & 0.002 & 1.320 & 0.012 & 0.054 \\
\hline S33 & 0.017 & 0.0007 & 0.002 & 1.560 & 0.013 & 0.077 \\
\hline S34 & 0.017 & 0.0008 & 0.002 & 1.510 & 0.013 & 0.083 \\
\hline S35 & 0.015 & 0.0009 & 0.002 & 1.450 & 0.012 & 0.076 \\
\hline mean & 0.004 & 0.0003 & 0.003 & 0.896 & 0.016 & 0.404 \\
\hline Max & 0.017 & 0.0009 & 0.027 & 4.460 & 0.095 & 5.690 \\
\hline Min & 0.001 & 0.0001 & 0.001 & 0.001 & 0.001 & 0.006 \\
\hline $\mathrm{SD}$ & 0.005 & 0.0002 & 0.005 & 1.129 & 0.020 & 0.958 \\
\hline $\mathrm{CV}$ & $119.96 \%$ & $93.95 \%$ & $146.93 \%$ & $126.06 \%$ & $127.10 \%$ & $236.95 \%$ \\
\hline
\end{tabular}

Table 2. Surface Water Quality Standards of the People's Republic of China (GB 3838-2002) and Drinking Water Guidelines from the World Health Organization (WHO) (4th ed., 2011) (mg/L)

\begin{tabular}{cccccccc}
\hline Elements & $\mathrm{I}$ & $\mathrm{II}$ & $\mathrm{II}$ & $\mathrm{IV}$ & $\mathrm{V}$ & Upper limit of WHO \\
\hline $\mathrm{As} \leq$ & 0.05 & 0.05 & 0.05 & 0.1 & 0.1 & 0.01 \\
$\mathrm{Hg} \leq$ & 0.00005 & 0.00005 & 0.0001 & 0.001 & 0.001 & 0.006 \\
$\mathrm{Cu} \leq$ & 0.01 & 1.0 & 1.0 & 1.0 & 1.0 & 2.0 \\
$\mathrm{Cd} \leq$ & 0.001 & 0.005 & 0.005 & 0.005 & 0.01 & 0.003 \\
$\mathrm{Zn} \leq$ & 0.05 & 1.0 & 1.0 & 2.0 & 2.0 & - \\
$\mathrm{Pb} \leq$ & 0.01 & 0.01 & 0.05 & 0.05 & 0.1 & 0.01
\end{tabular}

The symbol "-" indicates the absence of national standards due to the lack of health concerns surrounding levels found in drinking-water. 


\subsection{Correlation Analysis}

The single pollution index and Nemerow's pollution index of samplings were calculated (Table 3) using the national standard as defined by Class III as the standard value of the pollutants ( $\mathrm{Si}$ ). The assessment result of $P_{N}$ revealed that $74.28 \%$ of water samples were highly polluted. The highest values of the single pollution index of $\mathrm{Cd}$ and $\mathrm{Pb}$ were based on compared figures are 892.000 and 113.900 respectively.

Statistical analysis shows it is possible to have pollution from different pollution sources via the investigation of the variation concentrations of the six heavy metals in the surface water of the Yangping River. Therefore, it is necessary to re-identify pollution sources of the heavy metals and evaluate the pollution levels.

The correlation analysis showed that there are complex relationships between the single pollution index of heavy metals in the water samples (Table 4). From the analysis, the correlation coefficients of As-Hg and As-Zn are equal to $0.699(p<0.01)$ and

Table 3. Single Pollution Index and Nemerow's Pollution Index of Samplings in Yangping River

\begin{tabular}{|c|c|c|c|c|c|c|c|}
\hline Sampling NO. & $P_{i}$ (As) & $P_{i}$ (Hg) & $P_{i}(\mathrm{Cu})$ & $P_{i}(\mathrm{Cd})$ & $P_{i}(\mathrm{Zn})$ & $P_{i}(\mathrm{~Pb})$ & $\boldsymbol{P}_{N}$ \\
\hline $\mathrm{S} 1$ & 0.020 & 1.000 & 0.001 & 2.000 & 0.005 & 0.280 & 1.467 \\
\hline $\mathrm{S} 2$ & 0.020 & 1.000 & 0.001 & 1.000 & 0.005 & 0.160 & 0.753 \\
\hline S3 & 0.040 & 1.000 & 0.001 & 1.800 & 0.004 & 0.320 & 1.326 \\
\hline $\mathrm{S} 4$ & 0.060 & 1.000 & 0.009 & 76.000 & 0.030 & 8.400 & 54.677 \\
\hline S5 & 0.060 & 1.000 & 0.009 & 32.000 & 0.036 & 11.200 & 23.222 \\
\hline S6 & 0.040 & 1.000 & 0.001 & 4.200 & 0.005 & 1.100 & 3.063 \\
\hline S7 & 0.060 & 1.000 & 0.004 & 22.000 & 0.016 & 4.000 & 15.880 \\
\hline S8 & 0.020 & 1.000 & 0.001 & 1.400 & 0.001 & 0.960 & 1.067 \\
\hline S9 & 0.020 & 1.000 & 0.008 & 0.200 & 0.005 & 0.360 & 0.732 \\
\hline $\mathrm{S} 10$ & 0.060 & 2.000 & 0.027 & 108.000 & 0.086 & 113.800 & 84.687 \\
\hline S11 & 0.020 & 1.000 & 0.001 & 252.000 & 0.008 & 0.120 & 180.671 \\
\hline $\mathrm{S} 12$ & 0.020 & 1.000 & 0.002 & 46.000 & 0.008 & 7.200 & 33.149 \\
\hline S13 & 0.020 & 1.000 & 0.001 & 0.200 & 0.001 & 0.180 & 0.726 \\
\hline S14 & 0.040 & 1.000 & 0.002 & 120.000 & 0.008 & 9.200 & 86.230 \\
\hline S15 & 0.020 & 1.000 & 0.002 & 84.000 & 0.009 & 8.400 & 60.409 \\
\hline S16 & 0.020 & 1.000 & 0.001 & 1.200 & 0.005 & 0.300 & 0.899 \\
\hline $\mathrm{S} 17$ & 0.020 & 1.000 & 0.002 & 144.000 & 0.010 & 7.400 & 103.396 \\
\hline S18 & 0.040 & 1.000 & 0.001 & 1.000 & 0.005 & 0.140 & 0.753 \\
\hline S19 & 0.020 & 4.000 & 0.002 & 468.000 & 0.015 & 10.200 & 335.771 \\
\hline $\mathrm{S} 20$ & 0.340 & 2.000 & 0.009 & 36.000 & 0.095 & 8.800 & 26.058 \\
\hline $\mathrm{S} 21$ & 0.040 & 6.000 & 0.002 & 430.000 & 0.013 & 12.400 & 308.615 \\
\hline $\mathrm{S} 22$ & 0.080 & 6.000 & 0.001 & 114.000 & 0.015 & 1.680 & 81.878 \\
\hline $\mathrm{S} 23$ & 0.060 & 1.000 & 0.001 & 48.000 & 0.005 & 0.540 & 34.441 \\
\hline $\mathrm{S} 24$ & 0.040 & 6.000 & 0.002 & 892.000 & 0.016 & 14.200 & 639.836 \\
\hline S25 & 0.060 & 4.000 & 0.002 & 616.000 & 0.013 & 7.800 & 441.818 \\
\hline S26 & 0.040 & 1.000 & 0.002 & 42.000 & 0.008 & 4.800 & 30.229 \\
\hline $\mathrm{S} 27$ & 0.080 & 4.000 & 0.002 & 740.000 & 0.017 & 7.200 & 530.697 \\
\hline S28 & 0.060 & 2.000 & 0.005 & 52.000 & 0.023 & 24.000 & 37.904 \\
\hline S29 & 0.120 & 3.000 & 0.002 & 424.000 & 0.016 & 7.600 & 304.159 \\
\hline S30 & 0.100 & 2.000 & 0.001 & 138.000 & 0.009 & 3.200 & 99.032 \\
\hline S31 & 0.060 & 1.000 & 0.001 & 206.000 & 0.011 & 1.140 & 147.716 \\
\hline S32 & 0.300 & 8.000 & 0.002 & 264.000 & 0.012 & 1.080 & 189.436 \\
\hline S33 & 0.340 & 7.000 & 0.002 & 312.000 & 0.013 & 1.540 & 223.835 \\
\hline S34 & 0.340 & 8.000 & 0.002 & 302.000 & 0.013 & 1.660 & 216.689 \\
\hline S35 & 0.300 & 9.000 & 0.002 & 290.000 & 0.012 & 1.520 & 208.103 \\
\hline mean & 0.085 & 2.6571 & 0.003 & 179.171 & 0.016 & 8.082 & 128.838 \\
\hline Max & 0.340 & 9.0000 & 0.027 & 892.000 & 0.095 & 113.800 & 639.836 \\
\hline Min & 0.020 & 1.0000 & 0.001 & 0.200 & 0.001 & 0.120 & 0.726 \\
\hline SD & 0.102 & 2.496 & 0.005 & 225.865 & 0.020 & 19.151 & 161.886 \\
\hline
\end{tabular}


Table 4. Pearson's Correlation Coefficient (Lower-left Side of Table) and Corresponding Significance Levels (Upper-right Side of Table)

\begin{tabular}{|c|c|c|c|c|c|c|}
\hline Elements & As & Hg & $\mathrm{Cu}$ & Cd & $\mathrm{Zn}$ & $\mathrm{Pb}$ \\
\hline As & 1.000 & 0.000 & 0.769 & 0.321 & 0.046 & 0.691 \\
\hline $\mathrm{Hg}$ & $0.699^{* *}$ & 1.000 & 0.536 & 0.000 & 0.913 & 0.871 \\
\hline $\mathrm{Cu}$ & 0.051 & -0.108 & 1.000 & 0.460 & 0.000 & 0.000 \\
\hline $\mathrm{Cd}$ & 0.173 & $0.605^{* *}$ & -0.129 & 1.000 & 0.967 & 0.803 \\
\hline $\mathrm{Zn}$ & $0.339^{*}$ & 0.019 & $0.806^{* *}$ & -0.007 & 1.000 & 0.000 \\
\hline $\mathrm{Pb}$ & -0.070 & -0.028 & $0.886^{* *}$ & 0.044 & $0.672^{* *}$ & 1.000 \\
\hline
\end{tabular}

Where $* *$ indicates significant correlation at 0.01 level; * indicates significant correlation at 0.05 level.

0.339 ( $p<0.05$ ), respectively, suggesting a positive correlation exists between As and $\mathrm{Hg}$ but an insignificant correlation between As and Zn. The correlation coefficients of $\mathrm{Hg}-\mathrm{Cd}, \mathrm{Cu}-\mathrm{Zn}$, and $\mathrm{Cu}-\mathrm{Pb}$ are equal to $0.605,0.806$, and 0.886 respectively, which are also positively related. The above analyses showed that Hg, As, and Cd may be derived from the same sources or may be influenced by the same factor or factors. Similarly, $\mathrm{Pb}, \mathrm{Cu}$, and Zn might also share sources or be influenced similarly. In order to reveal the sources of these elements, PCA, and HCA analysis methods were applied.

\section{3. $\mathrm{HCA}$}

The HCA score plots described the characteristics of the samples and helped to determine temporal distribution; can be used for identifying categories of pollution sources [25]. Fig. 2 represents an HCA tree which was created using a Pearson correlation as measurement standard. From the results of the analysis, we can see two main clusters in the Fig. 2. Thus we can divide the heavy metals in the surface water of the Yangping River into two clusters. One cluster includes $\mathrm{Cu}, \mathrm{Pb}$ and $\mathrm{Zn}$, while the other is As, Hg and Cd. It has explained that six heavy metals contaminant may come from two kinds of different sources. The result of the HCA was consistent with that of the Correlation Analysis.

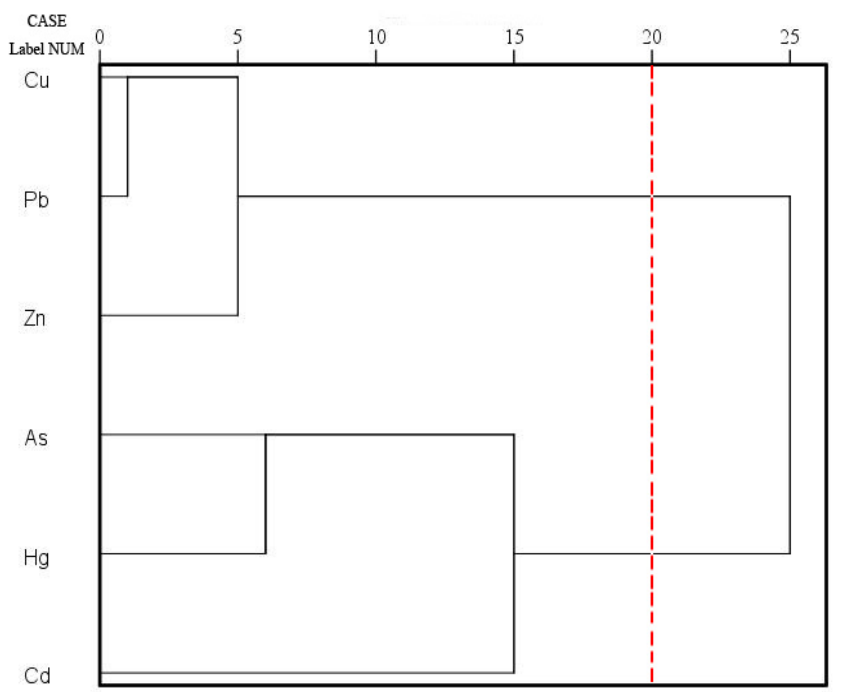

Fig. 2. HCA dendrogram of surface water samples.

\subsection{PCA}

In Fig. 3 there are two values of PCs greater than 1, therefore, there are two components. Both Table 5 and 6 are the results of PCA. The results show that two principal components (PCs) explained approximately $77 \%$ of the total variance. The first and second components explain approximately $43 \%$ and approximately $34 \%$ of the total variance respectively. The eigenvalues of rotated PCs are nearly equal to the initial components. Thus, according to the component matrix, loading coefficients more or equal to 0.600 are used to define separate groups.

The first principal component (PC1) includes $\mathrm{Cu}, \mathrm{Zn}$ and $\mathrm{Pb}$, the corresponding loading coefficients are 0.966, 0.903 and 0.905 respectively. The second principal component (PC2) includes As, $\mathrm{Hg}$ and $\mathrm{Cd}$, the corresponding loading coefficients are 0.789, 0.950 and 0.694 respectively (Table 6). By way of PCA, it becomes clear (Fig. 4) that $\mathrm{Pb}, \mathrm{Zn}$ and $\mathrm{Cu}$ are one group; $\mathrm{Hg}$, As and Cd comprise another group. This result coincides with the conclusions of both the correlation analysis and HCA. The concentration of the first group's $\mathrm{Cu}$ and $\mathrm{Zn}$ levels were under the III water quality standard, while the concentration of $\mathrm{Pb}$ extended far beyond the indicated standard. Therefore, the pollution sources of this group must have a close relationship with the smelting methods of lead ores, which is due to the fact the there are many lead plants near the river [26, 27]. From above analysis, we can draw the conclusion that lead can represent the contamination of the group.

In the second group, the positive loading modulus of $\mathrm{Hg}(0.950)$

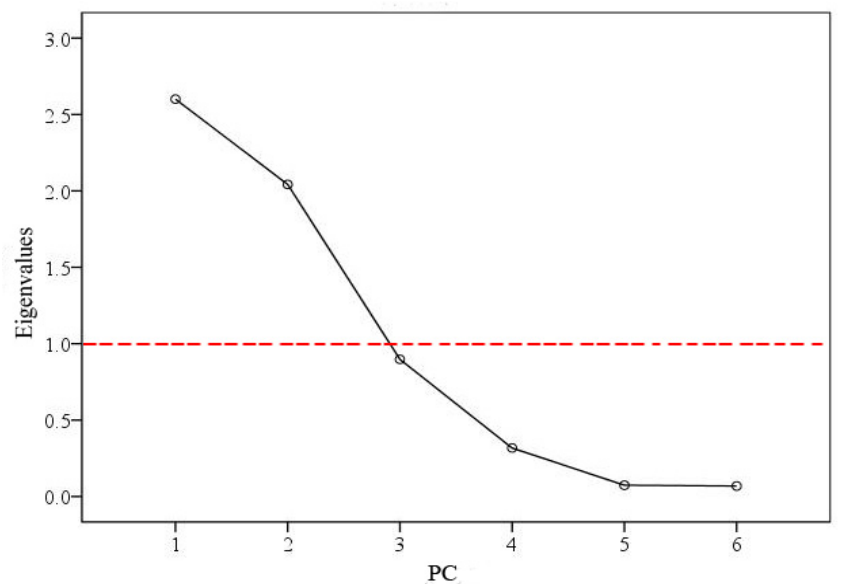

Fig. 3. Eigenvalues of each PC. 
Table 5. Total Variance Explained and Rotated Component Matrix of Water Samples

\begin{tabular}{|c|c|c|c|c|c|c|c|c|c|}
\hline \multirow{2}{*}{ Component } & \multicolumn{3}{|c|}{ Initial Eigenvalues } & \multicolumn{3}{|c|}{ Extraction sums of squared loadings } & \multicolumn{3}{|c|}{ Rotation sums of squared loadings } \\
\hline & Total & $\%$ of variance & Cumulative \% & Total & \% of variance & Cumulative \% & Total & $\%$ of variance & Cumulative \% \\
\hline 1 & 2.600 & 43.341 & 43.341 & 2.600 & 43.341 & 43.341 & 2.600 & 43.326 & 43.326 \\
\hline 2 & 2.042 & 34.036 & 77.376 & 2.042 & 34.036 & 77.376 & 2.043 & 34.051 & 77.376 \\
\hline 3 & .897 & 14.957 & 92.334 & & & & & & \\
\hline 4 & .317 & 5.290 & 97.624 & & & & & & \\
\hline 5 & .074 & 1.231 & 98.855 & & & & & & \\
\hline 6 & .069 & 1.145 & 100.000 & & & & & & \\
\hline
\end{tabular}

Extraction method, PCA

Table 6. Factor Loadings of Six Heavy Metals in the Yangping River

\begin{tabular}{ccccc}
\hline \multirow{2}{*}{ Heavy metal elements } & \multicolumn{2}{c}{ Component matrix } & \multicolumn{2}{c}{ Rotated component matrix } \\
\cline { 2 - 5 } & PC1 & PC2 & PC1 & 0.051 \\
PC2 & 0.389 \\
$\mathrm{As}$ & 0.174 & 0.789 & -0.023 & 0.464 \\
$\mathrm{Cu}$ & -0.011 & 0.950 & 0.374 & -0.048 \\
$\mathrm{Cd}$ & 0.966 & -0.129 & -0.030 & 0.339 \\
$\mathrm{Zn}$ & -0.043 & 0.694 & 0.345 & 0.070 \\
$\mathrm{~Pb}$ & 0.903 & 0.115 & 0.350 & -0.027 \\
\hline
\end{tabular}

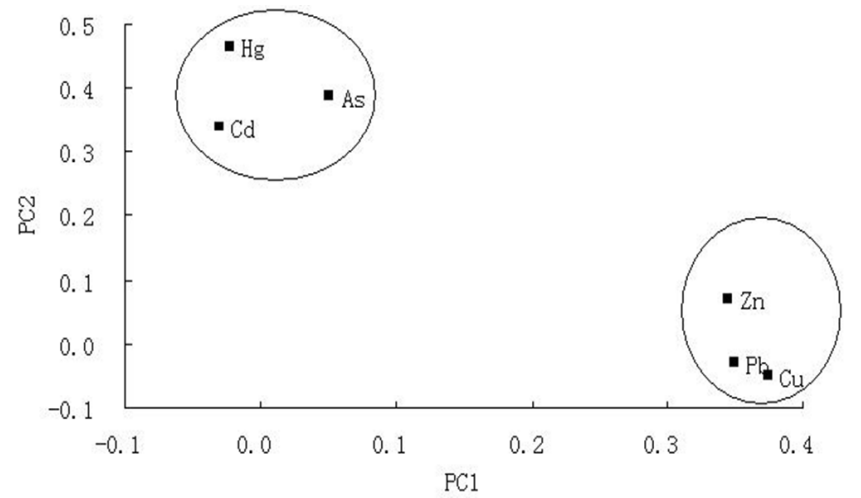

Fig. 4. Loading coefficients plot of heavy metals.

is higher than the other two heavy metals (As and Cd). Table 6 shows that the factor $\mathrm{Hg}$ is the highest value of the loading modulus. This illustrates that gold mining and gold ore processing have affected the water quality of the river. However, the single pollution index of $\mathrm{Cd}$ is greater than others. This illustrates that $\mathrm{Cd}$ pollution is more serious than $\mathrm{Hg}$ and As pollution in the PC2. All of the single pollution indexes $\left(P_{i}\right)$ of $\mathrm{Cd}$ are greater than other two heavy metals in this group. The contamination position is mainly located at sampling sites S19, S21, S24, S25, S27 and S29.

\subsection{Assessment of Heavy Metal Pollution}

There exist 26 water samples that have been categorized with a high degree of pollution according to the results of Nemerow's pollution index (Table 3). Moderate, low, and clean water samples categorizations include one, three, and five samples respectively (Table 7). The relative coefficient square is equal to 0.996 between $P_{\alpha n}$ and $P_{N}$, which indicates that the assessment result of the new method was in sync with Nemerow's pollution index (Fig. 5).

The results of both indicate shows that sample S13 was clean and the sample S24 contained high levels of pollution (Table 3, Table 7). The contents of S13 were collected at the mountain far from the town of Guxian. Meanwhile the contents S24 of were collected downstream of Guxian. The results are indicative of the fact that there are many gold mining and smelting workshops in Guxian, much of the waste water discharges into the Yangping River. Therefore, the value of $P_{a n}$ can serve as a new assessment index used to evaluate the heavy metal pollution of water samples. However, this method has only been used to monitor heavy metals pollution in the Yangping River, and is therefore only known to be acceptable. In future research, we hope to study more monitoring data in other sites of polluted surface water using this approach to advance the evaluation methods.

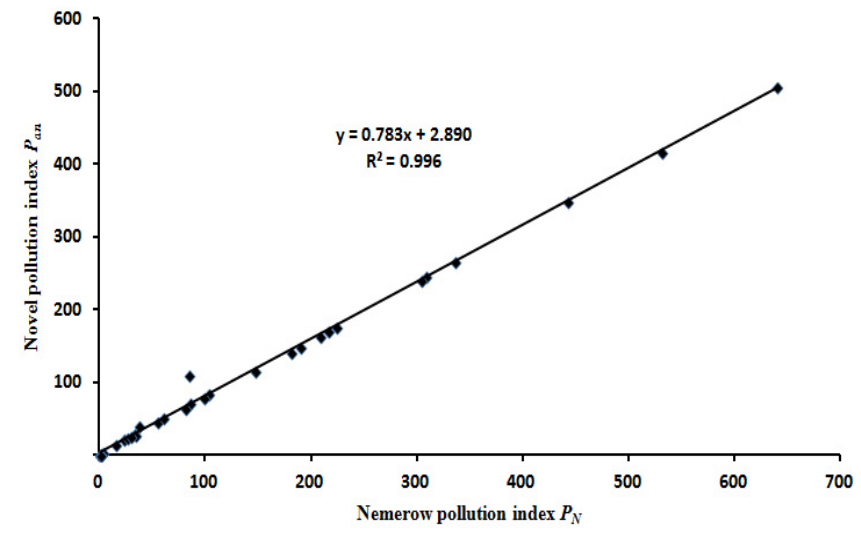

Fig. 5. The novel pollution index $P_{a n}$ can be compared to Nemerow's pollution index $P_{N}$. 
Table 7. The New Pollution Index of Samplings in the Yangping River

\begin{tabular}{|c|c|c|c|c|c|c|c|}
\hline Sampling NO. & $\boldsymbol{P}_{a n}$ & Sampling NO. & $\boldsymbol{P}_{a n}$ & Sampling NO. & $\boldsymbol{P}_{a n}$ & Sampling NO. & $\boldsymbol{P}_{a n}$ \\
\hline $\mathrm{S} 1$ & 1.24 & $\mathrm{~S} 11$ & 141.16 & S21 & 246.23 & S31 & 115.85 \\
\hline S2 & 0.63 & $\mathrm{~S} 12$ & 28.93 & S22 & 64.57 & S32 & 148.3 \\
\hline S3 & 1.15 & $\mathrm{~S} 13$ & 0.19 & S23 & 27.11 & S33 & 175.38 \\
\hline S4 & 46.25 & S14 & 71.24 & S24 & 505.72 & S34 & 169.83 \\
\hline S5 & 22.85 & S15 & 50.73 & S25 & 348.36 & S35 & 163.05 \\
\hline S6 & 2.84 & S16 & 0.8 & S26 & 25.63 & clean & 5 \\
\hline S7 & 14.08 & $\mathrm{~S} 17$ & 83.89 & S27 & 417.52 & low & 3 \\
\hline S8 & 1.21 & S18 & 0.62 & S28 & 39.68 & moderate & 1 \\
\hline S9 & 0.27 & S19 & 266.54 & S29 & 240.76 & high & 26 \\
\hline $\mathrm{S} 10$ & 110.55 & $\mathrm{~S} 20$ & 24.03 & S30 & 78.68 & & \\
\hline
\end{tabular}

\section{Conclusions}

Via the application of extensive statistical analysis, this article argues that the water of the Yangping River suffer from seriously heavy metal pollution as defined by the Surface Water Quality Standards of the People's Republic of China (GB 3838-2002) [27] and the Drinking Water Guidelines from the World Health Organization (WHO) (4th ed., 2011) [28]. The results of Pearson's correlation analysis, PCA and HCA, which all indicate that the elements $\mathrm{Cu}, \mathrm{Pb}$ and $\mathrm{Zn}$ belong to one contaminant group; while As, Hg, Cd belong to another. These groups of heavy metals might be derived from different pollution sources. The two principle components accounted for up to $43.341 \%$ and $34.036 \%$ of total variance respectively.

The new proposed assessment method overcomes the disadvantage of Nemerow's pollution index by utilizing the maximum value of the single factor index. Using linear regression analysis, the original assessment result of the proposing method is consistent with that of Nemerow's pollution index. This assessment method, however, may have some deficiencies and requires verification through more research in order to be applied to cases other water polluted sites.

\section{Acknowledgements}

The authors would like to thank two anonymous reviewers for their helpful comments on the previous version of the manuscript. Meanwhile, the authors also want to express their gratitude to everyone who provided raw materials and experiment equipment in the present study.

This study is jointly supported by the National Natural Science Foundation of China (Grant No. 41272377) and the National Youth Science Foundation of China (Grant No. 41302278).

\section{References}

1. Oves M, Khan MS, Zaidi A, Ahmad E. Soil contamination, nutritive value, and human health risk assessment of heavy metals: An overview. In: Zaidi A, Wani PA, Khan MS, eds.
Toxicity of heavy metals to legumes and bioremediation. Springer Vienna; 2012. p. 1-27.

2. Wang QR, Dong Y, Cui Y, Liu X. Instances of soil and crop heavy metal contamination in China. Soil Sediment Contam. 2001;10:497-510.

3. Nabulo G, Young SD, Black CR. Assessing risk to human health from tropical leafy vegetables grown on contaminated urban soils. Sci. Total Environ. 2010;408:5338-5351.

4. Dong J, Yang QW, Sun LN, et al. Assessing the concentration and potential dietary risk of heavy metals in vegetables at a $\mathrm{Pb} / \mathrm{Zn}$ mine site, China. Environ. Earth Sci. 2011;64:1317-1321.

5. Zhu X, Ji H, Chen Y, Qiao M, Tang L. Assessment and sources of heavy metals in surface sediments of Miyun Reservoir, Beijing. Environ. Monit. Assess. 2012;185:6049-6062.

6. Chandrasekaran A, Mukesh MV, Chidambaram S, et al. Assessment of heavy metal distribution pattern in the sediments of Tamirabarani river and estuary, east coast of Tamil Nadu, India. Environ. Earth Sci. 2015;73:2441-2452.

7. Sin YM, Wong MK, Chou LM, Alias NB. A study of the heavy metal concentrations of the Singapore River. Environ. Monit. Assess. 1991;19:481-494.

8. Nan Y, Liu W, Xie H, et al. Distribution and assessment of heavy metals in the surface sediment of Yellow River, China. J. Environ. Sci.-China 2015;39:453-459.

9. Zhang Z, Abuduwaili J, Jiang F. Heavy metal contamination, sources, and pollution assessment of surface water in the Tianshan Mountains of China. Environ. Monit. Assess. 2015; 187:1-13.

10. Salati S, Moore F. Assessment of heavy metal concentration in the Khoshk River water and sediment, Shiraz, Southwest Iran. Environ. Monit. Assess. 2010;164:677-689.

11. Thuong NT, Yoneda M, Ikegami M, Takakura M. Source discrimination of heavy metals in sediment and water of To Lich River in Hanoi City using multivariate statistical approaches. Environ. Monit. Assess. 2013;185:8065-8075.

12. Islam MS, Ahmed MK, Raknuzzaman M, Habibullah-AlMamun M, Islam MK. Heavy metal pollution in surface water and sediment: A preliminary assessment of an urban river in a developing country. Ecol. Indic. 2015;48:282-291.

13. Pekey $H$. The distribution and sources of heavy metals in Izmit Bay surface sediments affected by a polluted stream. Mar. Pollut. Bull. 2006;52:1197-1208. 
14. Adokoh CK, Obodai EA, Essumang DK, Serfor-Armah Y, Nyarko BJ, Asabere-Ameyaw A. Statistical evaluation of environmental contamination, distribution and source assessment of heavy metals (aluminum, arsenic, cadmium, and mercury) in some lagoons and an estuary along the coastal belt of Ghana. Arch. Environ. Contam. Toxicol. 2011;61:389-400.

15. Ma X, Hang Z, Tian M, et al. Assessment of heavy metals contamination in sediments from three adjacent regions of the Yellow River using metal chemical fractions and multivariate analysis techniques. Chemosphere 2016;144:264-272.

16. Jahanshahi R, Zare M. Assessment of heavy metals pollution in groundwater of Golgohar iron ore mine area, Iran. Environ. Earth Sci. 2015;74:505-520.

17. Xie Z, Sun Z, Zhang H, Zhai J. Contamination assessment of arsenic and heavy metals in a typical abandoned estuary wetland-a case study of the Yellow River Delta Natural Reserve. Environ. Monit. Assess. 2014;186:7211-7232.

18. Sahoo MM, Patra KC, Khatua KK. Inference of water quality index using ANFIA and PCA. Aquatic Procedia. 2015;4:1099-1106.

19. An Q, Wu Y, Wang J, Li Z. Assessment of dissolved heavy metal in the Yangtze River estuary and its adjacent sea, China. Environ. Monit. Assess. 2010;164:173-187.

20. Ying W, Yang Z, Shen Z, Tang Z, Niu J, Gao F. Assessment of heavy metals in sediments from a typical catchment of the Yangtze River, China. Environ. Monit. Assess. 2011;172:407-417.

21. Martinez JL, Raiber M, Cox ME. Assessment of groundwatersurface water interaction using long-term hydrochemical data and isotope hydrology: Headwaters of the Condamine River,
Southeast Queensland, Australia. Sci. Total Environ. 2015;536: 499-516.

22. Seongmook P, Futaba K, Shunhwa L. Assessment of water quality using multivariate statistical techniques: A case study of the Nakdong River Basin, Korea. Environ. Modell. Softw. 2007;22:464-475.

23. Sun W, Xia C, Xu M, Guo J, Sun G. Application of modified water quality indices as indicators to assess the spatial and temporal trends of water quality in the Dongiiang River. Ecol. Indic. 2016;66:306-312.

24. Bhutiani R, Kulkarni DB, Khanna DR, Gautam A. Water quality, pollution source apportionment and health risk assessment of heavy metals in groundwater of an industrial area in North India. Water Qual. Expo. Health 2016;8:3-18.

25. Dwivedi AK, Vankar PS. Source identification study of heavy metal contamination in the industrial hub of Unnao, India. Environ. Monit. Assess. 2014;186:3531-3539.

26. Zhang XM, Qiao CJ, Cai XD, et al. Characteristics of Yinjiagou polymetal-pyrite deposit related to pulse magmatic intrusions in Henan, China. Global Geol. 2008;27:137-145.

27. SEPAC (State Environmental Protection Administration), AQSIQC (Administration of Quality Supervision, Inspection and Quarantine of China). Environmental quality standards for surface water of the People's Republic of China (GB3838-2002). 2002. (in Chinese).

28. Organization WH. Guidelines for Drinking-water Quality 4th ed. WHO, Geneva, Switzerland; 2011. 